\title{
Research and Exploration on Flipped Classroom Learning Model Based on Micro-lesson
}

\author{
Liangtao Yang \\ Shanghai Second Polytechnic University, Shanghai, China \\ E-mail:ltyang@sspu.edu.cn
}

Keywords: micro-lesson, flipped classroom, learning model

\begin{abstract}
Flipped classroom has become the focus for the global education community, but the existing research ignored the design and convergence of the activities before class, in class, and after class in the course of the implementation of the flipped classroom. Aiming at the key problem of the flipped classroom, this paper builds a lipped classroom learning model based on the micro-lesson by referring to the domestic and foreign existing micro-lesson resources and activities. The model achieves the knowledge construction and internalization by discovering problem before class, solving the problem in class and knowledge consolidation after class.
\end{abstract}

\section{Introduction}

As early as 2000, American scholars, MaureenLage, Glenn Platt and Michael Treglia, have introduced flipped classroom and achievements in the relevant papers. With the development and popularization of the Internet, the flipped classroom teaching mode is gradually popular in the United States. By 2011, the flipped classroom has been well known by many teachers, and has become the focus of the teaching model in the global education community. In the flipped classroom teaching mode, students learn the knowledge in the classroom, teachers and students communicate with each other to complete the task of teaching. Flipped classroom can not only improve students' autonomous learning ability, but also play the students' creative ability, and achieve better teaching results. [1]The implementation of the flipped classroom needs the support of information technology, because the flipped classroom is through the teachers to make teaching resources, student learning teaching resources in class. According to the students' individual learning ability, students can control individual learning and learning content. And finally students can achieve knowledge internalization in the classroom through the exchange and collaboration.

Micro-lesson was first proposed in 2008 by David Penrose, who is San Juan college senior designer, and college teaching online service manager. In 2013, the concept of micro-lesson is a "micro" craze in the education sector in China, and it has been recognized by many experts and teachers in education field. How to guide students to complete autonomous learning through micro-lesson, and use flipped classroom to carry out learning by the discussion, collaboration and other easy and lively teaching forms, it becomes a new research focus. Micro-lesson and flipped classroom need to be implemented into the teaching application. Flipped classroom, as a teaching method, has become a hot issue for domestic and foreign scholars, educators, research and practice, its positive role in the classroom, positive effect on teaching has been unanimously endorsed by scholars and practitioners. However, the existing research ignored the research and design of 
transferring knowledge. For flipped classroom, the key is the design and convergence of activities before class, in class and after class. In order to achieve activity integration before class, in class and after class, the author studied and explored the problem by combining his own course teaching.

\section{Micro-lesson and flipped classroom}

\subsection{The Connotation and Characteristics of Micro-lesson}

Micro-lesson, as a new form of teaching resources and educational information, not only can be used as auxiliary teaching resources, but also can be used as learning resources, has great development potential and prospect. Therefore, the research on the micro-lesson has become a new research focus in the field of educational information technology. At present, many scholars have defined and interpreted the meaning of micro-lesson. Its core and the idea is consistent, but has not formed the unified concept to define.

$\mathrm{Hu}$ Tiesheng has made the contrast and induction about the micro lesson in recent years. Jiao Jianli believes that micro-lesson is a short form of online teaching video to explain a knowledge point. Yu Shengquan thinks that the micro-lesson is not simply learning resources, but also is the micro resources based on the additional teaching services of the small curriculum. It has a complete teaching structure, including micro resources, learning activities and arrangements, learning effect and evaluation, curriculum learning certification and education services, etc....

In a broad sense, any teaching form can achieve micro teaching, but the video including the picture, the text, and the sound of a variety of forms of information can achieve the most effective teaching in a short period of time. Therefore, the micro-lesson is to small and micro video as the main carrier, and related with teaching design, courseware, exercises, learning guidance and other support materials. Micro-lesson carries out the teaching activities for a knowledge point or teaching link and, with the help of online learning environment, the implementation of teaching activities and education services. [2] The core content of the micro-lesson is the teaching micro video for a single point of knowledge or a teaching link, teaching goal is clear, the theme is bright, the content is short. At the same time, but also contains the relevant teaching and the theme of the micro lesson plans, courseware, micro practice, reflection, evaluation of auxiliary teaching resources and exercise test.

We believe that the micro-lesson has the following characteristics: (1) educative nature. Micro-lesson, as short online education resources, can solve the practical problems of teaching; (2) the purpose of. Micro-lesson has a clear teaching purpose, teaching objectives and teaching content, teaching activities, in the most effective way and the shortest time to achieve teaching objectives; (3) interesting. Micro-lesson should be interesting, to attract learners enthusiasm, active learning, rather than boring to explain; (4) sharing. Micro-lesson, as a new learning resource, can adapt to mobile learning, ubiquitous learning and online learning, should have a wide range of sharing, as far as possible to promote the use of free, cancel all kinds of browsing restrictions, etc....

\subsection{Design of Micro-lesson in Flipped Classroom}

Micro teaching is a new teaching model of the network. It breaks subject knowledge into concise and complete structure, which can be used for collective teaching in the classroom, but also can be used for individual teaching outside the classroom, and especially meets with the master learning theory of Bloom. Bloom believes that as long as enough time and proper teaching, almost all of the students can reach the level of mastery for almost all of the teaching content. The difference of students' learning ability can' $t$ decide whether the students can learn the content and the quality of the study, but only decide how much time the students spend to achieve the mastery of the content. Under the guidance of the Bloom idea: all students can learn, in the collective teaching as the basis, complemented by appropriate and timely feedback of teaching and guidance, provide individualized 
help suitable for each student learning and the extra time required, so that the majority of students to achieve the curriculum objectives required to master the standard. Therefore, in the hands of Bloom in the process of learning, the learning task is divided into many small teaching objectives, and then the tutorial is divided into a series of small learning units, learning knowledge, which have rigorous logic relationship between elements. Teachers use appropriate teaching methods to organize teaching, and make some simple diagnostic tests for each learning unit. [3]

The essence of the micro-lesson is a micro network course, and a complete network course can also be composed of a number of micro courses closely related to the teaching of knowledge. Micro-lesson, as an important part of the flipped classroom, directly determine the effect of knowledge transfer before the classroom, and affect the design of teaching activities in the classroom, so as to affect the final teaching effect. It is not supposed to be a complete classroom, but a part of the classroom or a set of teaching activities, and it is demonstrated through the network teaching platform. The micro-lesson includes the micro video which record the teacher's explain and demonstration, and at the same time it also includes case materials and other resources, courseware, learning resources; and the micro "exercise" mainly, supplemented by answering questions, online testing, online survey of autonomous learning activities and learning feedback.

The selection of teaching objects and teaching content must be based on the analysis and extraction of teaching objectives, which needs to make teaching video and network teaching resources meet with the actual teaching needs. In addition, we also need to set up online answering learning feedback according to the needs of exercise, provide an information learning environment, timely understanding of the students' learning status and problems, and then can make more targeted counseling. Learning time and difficulty of micro-lesson should be based on the specific classroom teaching content, it should not be longer than 15 minutes, the completion of the whole micro class learning time should be controlled in about 30 minutes.

\section{Design of Flipped Classroom Learning Model Based on Micro-lesson}

\subsection{Theoretical Basis}

To construct the learning model, we first of all should sort out the process and follow the principle of teaching mode design with a certain theoretical support. We need grasp the three theories in the design process: the master learning theory, the constructivism learning theory, and the theory of self-organization learning. The master learning theory suggests that students can control their own learning process. The students can arrange and control their own learning according to their own situation. After the process of knowledge acceptance and memory, students need to take the initiative to build their own way. Self-organization learning theory is a kind of development and innovation of learning. Based on the three theories, the design of teaching mode should follow the principles: the classification and stratification, the variety of activities, the students is mainly and the teacher is complementary.

Flipped classroom is not only the simple flip of teaching structure, is a subversion of the traditional classroom, after the turnover of classroom teachers is not only teaching, more to guide and facilitator of the learning process, students are changed from the original platform under the passive "audience" in teaching activities to actively participants. According to the different stages and different disciplines, different types of courses, flipping way may be diverse, but the basic idea is the same. The effective flipped classroom has the following important features: changing students from passive audience into active learners; needing information technology; construction and the internalization of the students' knowledge by all kinds of activities; helping student master more challenging concepts in class time, cultivating the ability to solve practical problems. During the design of the flipped classroom learning model, we should follow the following relevant design 
principles:

Principle one: to be conducive to the construction and internalization of student knowledge. Constructivism holds that knowledge is not taught by teachers, but the students get by the way of meaning construction. In flipped classroom, the traditional knowledge transfer is put in the classroom before the class and adds in the interaction of teachers and students to collaborative activities. The teacher should give the classroom stage to the students and become the coordinator and guider, so as to mobilize the students, to stimulate students' learning activity, to better reflect the dominant position of students, so that students can better complete the construction and the internalization of knowledge.

Principle two: to be conducive to the realization of hierarchical teaching. According to the cognitive load theory, the traditional adopt the same teaching content and teaching organization. If the students' cognitive load is low foundation, which causes waste teaching time and the basis of poor students' cognitive load is too high. Therefore, in the process of flipped classroom, we should provide students with enough micro video and related learning resources. Students can flexibly choose of learning resources, arrange learning time according to their own foundation, do not have to worry about whether the impact of other students in the process. Students can watch video repeatedly, do not have to worry about the omission of knowledge points, so as to achieve a true layered education, personalized learning.

Principle three: to be conducive to the students to master learning. American psychologist Bloom put forward the "master learning theory" that believes as long as the best teaching and give sufficient time, most learners can get excellent results. In the flipped classroom process, we should create a comfortable learning environment for students and create a relaxed learning atmosphere, the students do not like listening in class that feel nervous, get rid of the progress of teaching group in the teaching mode of problem, learning is no longer limited by time, so that students can learn at their own pace.

\subsection{The Implementation Process of Learning Model}

According to the characteristics and design principles of the flipped classroom, after referring to the practical application of "flipped classroom", we designed the "flipped classroom" application mode based on the micro-lesson, as shown in Figure 1. This model realizes the knowledge transfer, knowledge construction and internalization, knowledge consolidation and development by discovering problem before class, solving the problem in class and knowledge consolidation after class. [4]

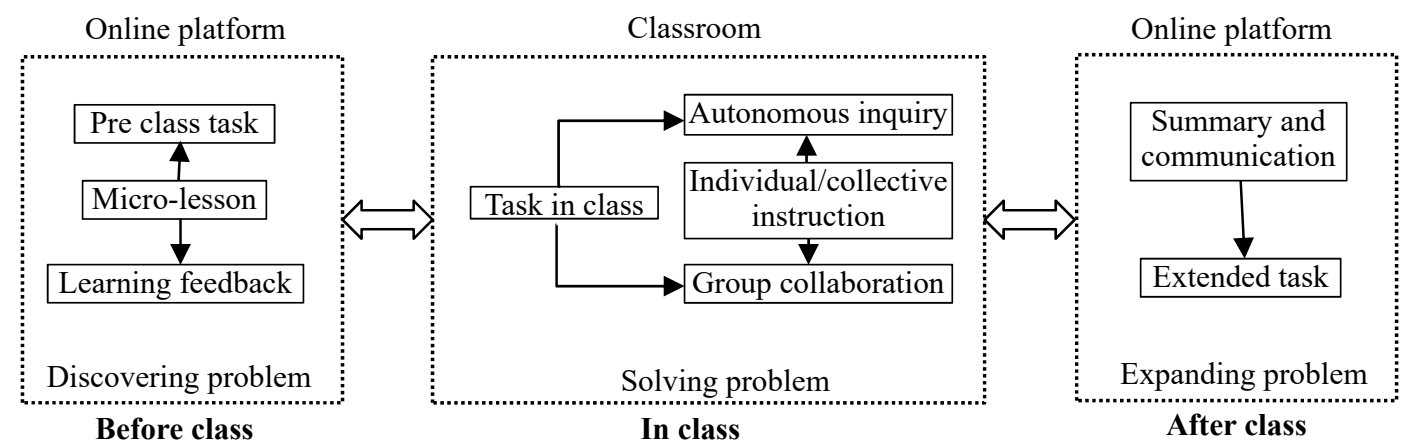

Fig. 1 the implementation process of learning model

The preparation stage before class: The teacher should resort the unit teaching content and separate it from the content of the teaching and demonstration, and determine the teaching purpose and content of the micro lesson according to the needs of the teaching arrangement. Next, collect 
learning resources, complete the teaching design of micro-lesson, and then make micro video. We should pay attention in the process of the fabrication of micro video: (1) micro video can be recorded by recording screen and voice form; (2) the video should include the occasional teachers camera to increase the teaching reality sense; (3) we should appropriately add indicate information to facilitate students to grasp the key point and the difficulty in the video; (4) considering the students' cognitive load, the length of the video should be controlled within 15 minutes. Finally, the micro video and other learning resources should be uploaded to the network teaching platform, set the task for the micro class, and build online Q \& A, online discussion and other information learning environment.

Under the guidance of learning task, students complete learning by using micro-lesson before the class. Within the specified time, the students complete the learning task and achieve the knowledge transfer through watching the micro video, participating in online Q \& A, discussion and other aspects of the task to. Teachers obtain the effect of micro-lesson and find the problem of students through correcting the task completion of the students, analysis of online Q \& A and discussion of the situation. If a student is not able to understand a part of the micro-lesson, he can refer to the relevant resources provided by the teacher to supplement. If the students still can't solve the problem, he can put the problem back to the teacher. In this process, the students not only should feedback the problem which can't be solved to teachers, but also need to put their own micro-lesson learning summary display to the teacher. This display can be based on their expertise to play, such as the students who have good oral ability can make their own learning experience recorded into a video. Students with strong operating ability can prove their understanding of the micro-lesson through some small production. Students with strong writing skills can display their own learning through a copy of an electronic manuscript or PPT. To assess the students through the diversity of the display, which accord with the student's personalized learning, can promote the cultivation of students' innovative ability.

The stage of internalization in the classroom: the teacher should give the time and space to the students in the classroom, and help students learn. This process can be a discussion, a test, can also be a small project. According to the student learning situation before the group, there are mainly divided into 3 major levels. For some students who do not master the basic theoretical knowledge, you can arrange a small test to confirm their mastery of the content of the project. If some students grasp the basic knowledge, only to certain knowledge of the common questions, you can set up a discussion group, teachers should guide students to discuss or explain the relevant difficulties. For students who have a good grasp of the project knowledge, then enter the next step. [5]During this period, teachers need to be counseling, advice, answer, and need to record the evaluation process which can be the evaluation of students or teachers after observation.

The consolidation stage after class: the teacher can collect relevant teaching contents to develop learning resources and expansion the task, the students who have spare capacity can challenge the expansion task to consolidate and expand the knowledge (skill). For the students who have not a good grasp, teachers need to provide additional supplemental learning. Teachers should advise students to access some information after class or watch some learning videos or do some exercises. Only when teachers confirm students' mastery of knowledge, they can carry out the next stage of learning.

In learning process, the teacher should highlight the students as the center. With the help of teacher, students complete the course learning to improve the students' autonomous learning ability by using the micro-lesson. In the whole learning process, students can carry out the course learning according to their own learning progress, and carry out personalized display according to their own special skills, which enhance the students' innovation ability. The whole learning process runs through the micro-lesson learning, the use of micro-lessons make the whole learning course more 
solid foundation knowledge, more professional systematic and comprehensive knowledge more. The whole learning process takes the students as the center and the flipped classroom presents a new challenge to the teachers. Therefore, the teachers' information abilities are the key to the success of the flipped classroom.

\section{Conclusion and Prospect}

The flipped classroom learning mode Based on micro-lesson mainly highlight the three points. The first is to change the role of the students, and we should pay more attention to cultivate the students' ability of independent learning and problem-solving skills. In addition, we must change the previous one-way knowledge transfer, and deepen the content of knowledge in the discussion, collaboration and other teaching activities. The two is the transformation of the role of teachers. We should reconstruct the harmonious relationship between teachers and students. We should change teachers' superior role in the traditional teaching mode of teacher. In addition to the role of professor, teachers but also are resource builders, and guider in questions and learning activities to protect the students form a complete knowledge system. The three is to pay attention to the hierarchical classification of teaching process, pay attention to individual training and innovation ability training. The students have their own learning plots, learning content, progress by their own grasp, and allow students to participate boldly in the examination of innovation. Aiming at the design and convergence of the activities before class, in class, and after class, this paper puts forward a "flipped classroom" learning mode based on the micro lesson. The model achieves the knowledge construction and internalization by discovering problem before class, solving the problem in class and knowledge consolidation after class. The flipped classroom learning mode based on the micro-lesson can effectively eliminate some drawbacks of the traditional teaching, but it needs to observe the application effect in the continuous practice, and constantly sum up and improve. In addition, the learning model is also needed to further improve the effectiveness of students' performance.

\section{References}

[1] $\mathrm{Hu}$ Tiesheng, Huang Mingyan, Li Ming. The Three Stages of Micro-lecture Development and Its Enlightenment[J]. Journal of Distance Education, 2013,(4):36-42.

[2] Hongjie Zhu, Yun Zhu. A discussion on the flipped classroom and its effective implementation strategy. [J]. E-Education Research, (2013) (8): 79-83.

[3] Yang Huang, Jianyang Liu, Peipei Yin, Lin Chen. Reflections on the "the Flipped Classroom" Teaching Design. [J]. Modern Education Technology, (2014) (12): 100-106.

[4] Wenliang Guo, Xuexin He. Flipped Classroom: background, Idea and Features. [J]. Theory and Practice of Education, (2015) (11): 3-6.

[5] Liu Rui, Wang Haiyan. The Design and Practice of "Flipped Classroom" Teaching model Based on Micro-lesson[J].Modern Education Technology, 2014,(5):26-32. 